\title{
A Study on the Effect of Various Air Flow Channels on the Efficiency of Mouthguard Design
}

\author{
E. A. Rahim ${ }^{1}$, Z. Ngali, M. S. Wahab, A. S. A. Sani, Z. Mohid, S. A. S. Anuar and \\ S. N. M. Yahaya \\ Faculty of Mechanical and Manufacturing Engineering, Universiti Tun Hussein Onn Malaysia, Parit Raja, \\ 86400 Batu Pahat, Johor, Malaysia \\ 1 erween@uthm.edu.my
}

\begin{abstract}
Proper selection of the mouthguard design can result in better breathing and speech performance during sports activities. This study emphasizes the design of air flow channels on mouthguard, which is very scarce to be found in literature so far. Air flow simulations based on actual design of mouth mould wearing a mouthguard using computerised fluid dynamics (CFD) simulation are carried out. Modelling and simulation analysis are conducted through various air flow channel designs utilizing a stock mouthguard as a benchmark. The selection criterion was based from previous dental studies which emphasized on the good effect of high exhale flow rate and low exhale pressure when designing the mouthguard's air flow channel. Based from the current simulation results, it is apparent that the developed model satisfied those criterions and might be proposed for fabrication.
\end{abstract}

Keyword-Air flow, CFD, Design, Mouthguard, Simulation modelling

\section{INTRODUCTION}

Orofacial trauma or parts injuries of a human locomotor system has brought an increase awareness to the health problems associated with sports which involved collision and contact sports such as boxing, American football, track-and-field events or even for the more extreme sport recreational activities e.g. mountain biking, skateboarding and roller-skating [1]. However, due to the discomfort and the difficulty in breathing as well as in speaking to the users, feelings of uneasiness have limited the frequency of mouthguard usage among professional athletes as well as individuals [2].

Although many reports have been published on the efficacy of mouthguard in protecting from any oral injuries, there are still some space of improvement that can be fine-tuned. Material selections, fabrication method, mouthguard design, side effects, comfortability, durability, easy-to-clean, speech and breathing obstruction are some controversial issues that need to be addressed in mouthguard manufacturing as well as to the wearers. In this current study, a design study analysis was conducted to propose an effective air flow channel design that may increase comfortability as well as to increase athlete's performance by properly reducing the breathing obstruction during sports activities while wearing mouthguard to prevent injuries [1-3].

There are three types of mouthguards that are available such as ready-made stock, mouth-formed boil-andbite and custom-made mouthguards. Table I depicts the type of mouthguards together with their advantages and disadvantages. The basic differences of them are based on their cost, comfort and durability during use. The most effective mouthguard should provide comfortability, tear resistant and should fit properly to the mouth of the wearer [4,5]. Problems associated with breathing and speaking obstruction while using mouthguards can be minimized by applying a proper design. A study has reported that coaches and trainers were keen to use a properly constructed custom-made mouthguard that can minimize the common complaints made by their athletes [1]. It is also necessary to educate the athletes including the coaches and other related personnel about the necessity to wear mouthguard as it provides mouth protection and keep healthy smiles intact throughout the day.

By means of a 3D sensor and a 3D solid modelling software, a model for computerised fluid dynamics (CFD) simulation analysis was conducted to evaluate the air flow channel design benchmarked against the model of a stock mouthguard that is available in the market. The results in terms of air flow velocity, area of air flow channel and the air pressure inside the mouth cavity were analysed and the best design was selected in accordance to the reduction of these process outputs. 
TABLE I. Types of Mouthguard

\begin{tabular}{|c|c|c|c|}
\hline \multirow[b]{2}{*}{$\begin{array}{c}\text { Types of } \\
\text { mouth guard }\end{array}$} & Stock mouthguard & Boil \& bite mouthguard & Custom fit mouthguard \\
\hline & & & \\
\hline Advantages & $\begin{array}{ll}\text { - } & \text { Ready stock } \\
\text { - } & \text { Low price } \\
\text { - } & \text { Available at sport } \\
& \text { stores }\end{array}$ & $\begin{array}{l}\text { - Ready stock } \\
\text { - Available at sport } \\
\text { stores } \\
\text { - Can be adjusted to } \\
\text { the user's mouth size }\end{array}$ & $\begin{array}{l}\text { - Best protection } \\
\text { - Best } \\
\text { comfortability }\end{array}$ \\
\hline Disadvantages & $\begin{array}{l}\text { - Low protection } \\
\text { - Low comfortability } \\
\text { - Not recommended } \\
\text { by dentist }\end{array}$ & $\begin{array}{l}\text { - Moderate price } \\
\text { - Moderate protection }\end{array}$ & $\begin{array}{ll}\text { - } & \text { Costly } \\
\text { Special order at } \\
\text { dental clinic }\end{array}$ \\
\hline
\end{tabular}

\section{Methodology}

The present study aims to analyse the custom air channel design between the new and existing mouth guards available in the market. A mouth mould was fabricated to facilitate the model of human mouth when and without wearing a mouth guard. The model was then used as a pilot model for scanning purposes. A 3DAdvanced Top Metric Sensor (ATOS) was used for the model scanning processes. An actual and precise appearance of a mouth model is converted into a digitalize data image (STL). The complete scanned data was then edited by using Geomagic software to transform the 3D scan data and to mesh the polygon of the model into an editable 3D digital model. The final 3D model is saved in IGES format file for further analyses and modelling through Solidwork software.

\section{A. Air Channel Design}

The internal volume of the mouth cavity was determined through a series of calculation on the Solidwork model. The internal mouth cavity volume while wearing a mouth guard is $32201 \mathrm{~mm}^{3}$ while without a mouth guard is $24111 \mathrm{~mm}^{3}$. An increment of approximately $33.5 \%$ of the internal volume when wearing a mouth guard was determined from the model. This result was used as a reference for the modelling of an internal mouth cavity for the simulation purposes. To ease the simulation process, a new model of internal mouth cavity was designed to match exactly with the actual shape of the 3D model internal mouth cavity as shown in Fig. 1.

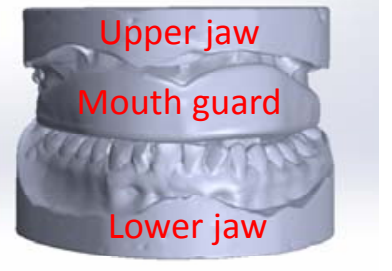

a)
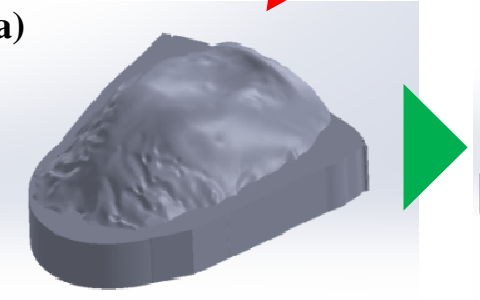
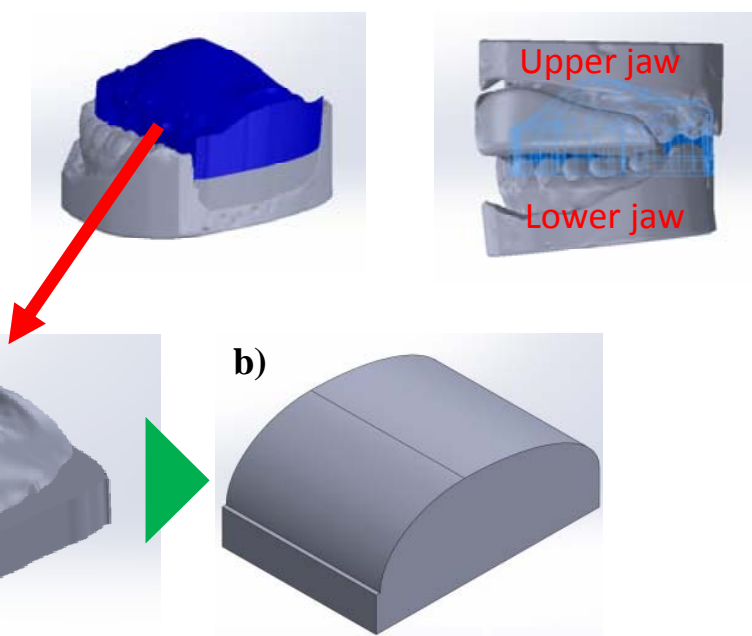

Fig. 1. Internal mouth cavity model: (a) Actual 3D model; (b) Simplified 3D model. 
The new air channel features were designed and attached to the simplified internal mouth cavity model for further simulation analysis. A series of five new air channel features in regards of different hollow design (D1 D5) through the mouth guard air flow channel were drawn and generated as exhibited in figure 2 for the simulation models. A stock model with an existing air flow channel (DN) was used as a benchmark model for comparison to the simulation results. The total calculated area of the hollow through the mouthguard's air flow channel is shown in Fig. 2.

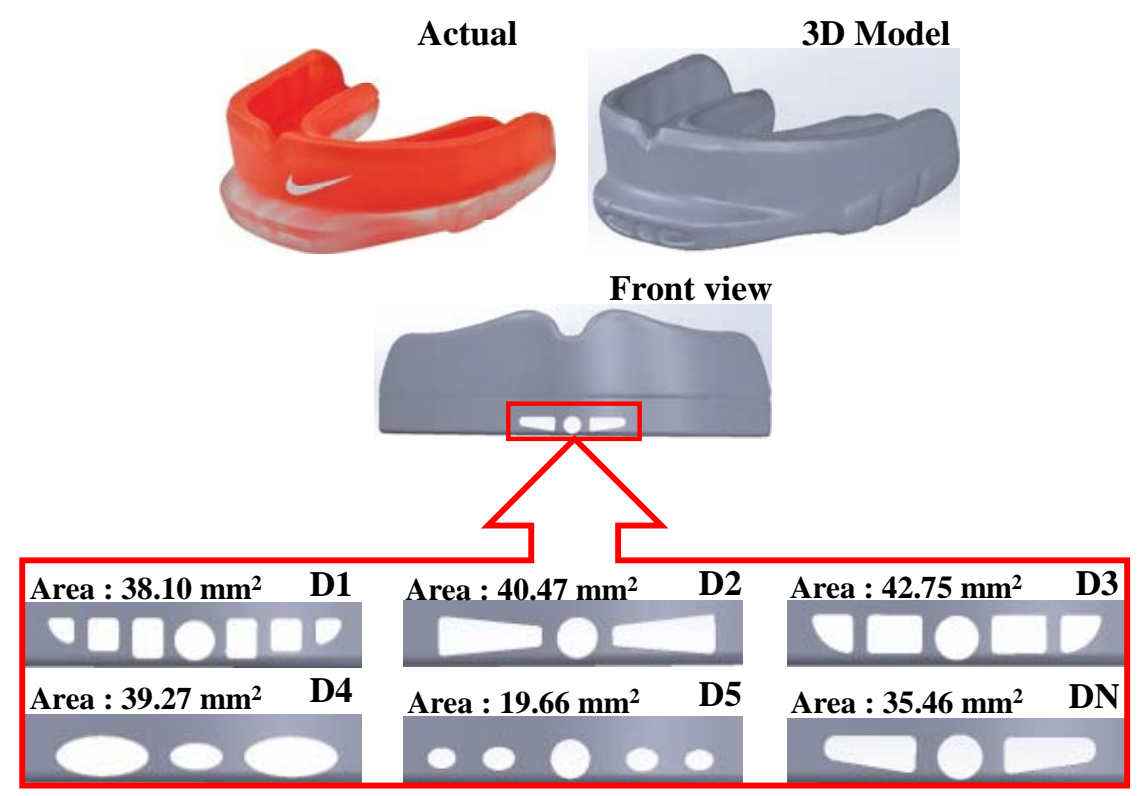

Fig. 2. Design of hollow through the mouthguard's air flow channel.

\section{B. CFD Simulation Process}

The air flow through the air channel features were analysed by using an ANSYS CFX software. Prior to the ANSYS simulation process, the geometric model which was designed in Solidwork was imported into the ANSYS Workbench 14.0 for a model meshing process. A boundary condition for the model was selected and set to the CFX Setup prior to the calculation analysis. The results of the simulation analysis can be displayed in terms of contour, velocity vector, streamlines, path lines, and streak lines and can be visualized in graphics, animations, plots and reports. Fig. 3 shows the example of simulation environment set on the ANSYS software. The data of the simulation results were exported for visualization and analysis purposes.
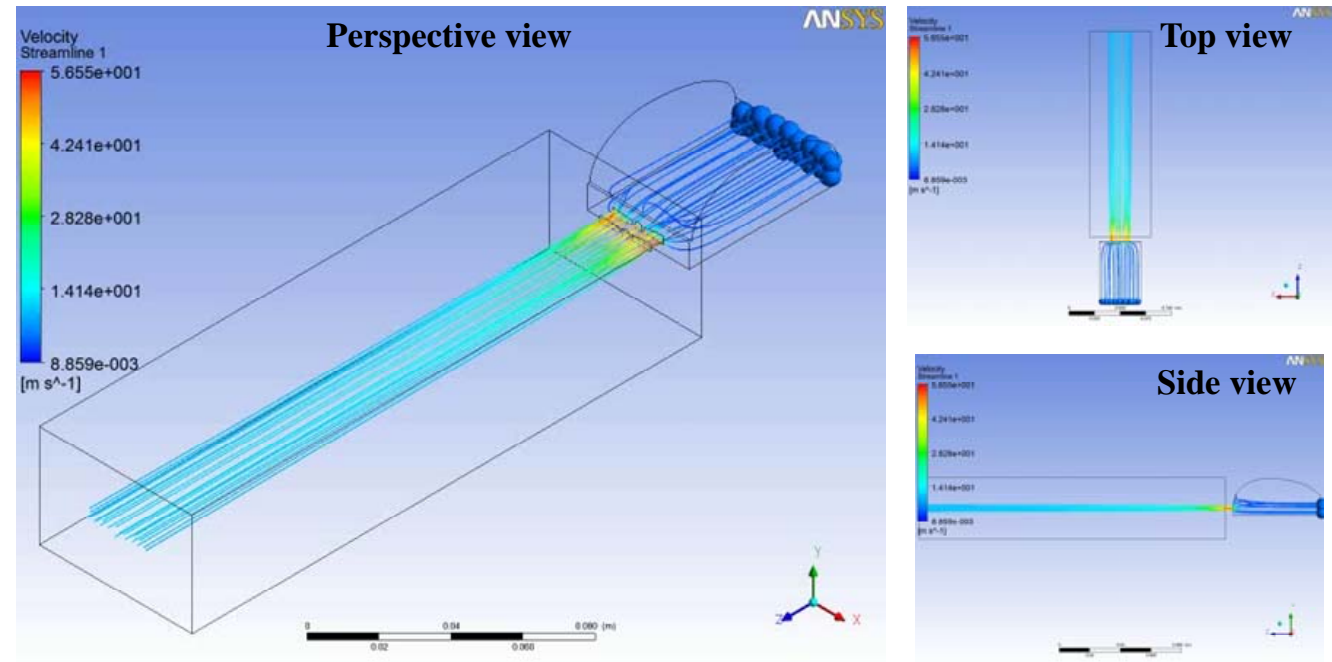

Fig. 3. Simulation environment of ANSYS.

The simulation process was based from the input parameters that control the output result. Volumetric flow rate equation and mass flow rate continuity equation were used to get the input velocity for the boundary condition. The meshing used on the advance size function is the proximity and curvature, a fine relevance centre and a high smoothing. There are no significant changes on the velocity result if the mesh relevance centre and the smoothing were varied respectively. Thus, the numerical check on mesh independency was fulfilled. 
Another boundary condition set prior to simulation was no heat transfer effect. The fluid material used is air at $25^{\circ} \mathrm{C}$ with a reference pressure of 1 bar. The inlet boundary was set to be air flow with initial velocity of 4.74 $\mathrm{m} / \mathrm{s}$ while the atmospheric boundary was set to be an opening boundary type with a relative pressure of $0 \mathrm{~Pa}$. The convergence criterion of the flow dynamics was set between 1 to 25 iterations in order to produce an ideal air flow with no backflow occurring inside the mouth area. The validation of the simulation was conducted through the continuity equation of mass flow rate.

\section{III.RESULTS AND DISCUSSION}

\section{A. Build-Up Pressure}

Simulation analysis was performed in order to determine the maximum exhale flow pressure. In this study, the pressure built in the mouth cavity was inversely influenced by the area of the hollow design. This correlation can be represented by Pascal equation, whereas the build-up pressure will increase with decreasing value of air flow channel area. Table II shows that D5 depicts the highest pressure build up in the mouth cavity model compared to others. D5 possesses the lowest total calculated hollow area of the mouthguard's air flow channel. The lowest build-up pressure is expressed by D3, which depicted the largest area. The increase in jaw diameter due to build up pressure may cause jaw joint pain, which is also known as temporomandibular joint (TMJ) disorder [6,7].

Therefore, lower pressure is one of the main criteria in selecting the most appropriate design of the mouthguard's air flow channel. Furthermore, the low pressure build up caused by the bigger area of the airflow channel may improve the upper respiratory airways of the mouthguard wearer. Study has shown that the increase in the size of upper respiratory airways by jaw-repositioning effect when using mouthguards may improve the aerobic performance of the athletes $[6,7]$.

TABLE II. Results of Air Flow Pressure

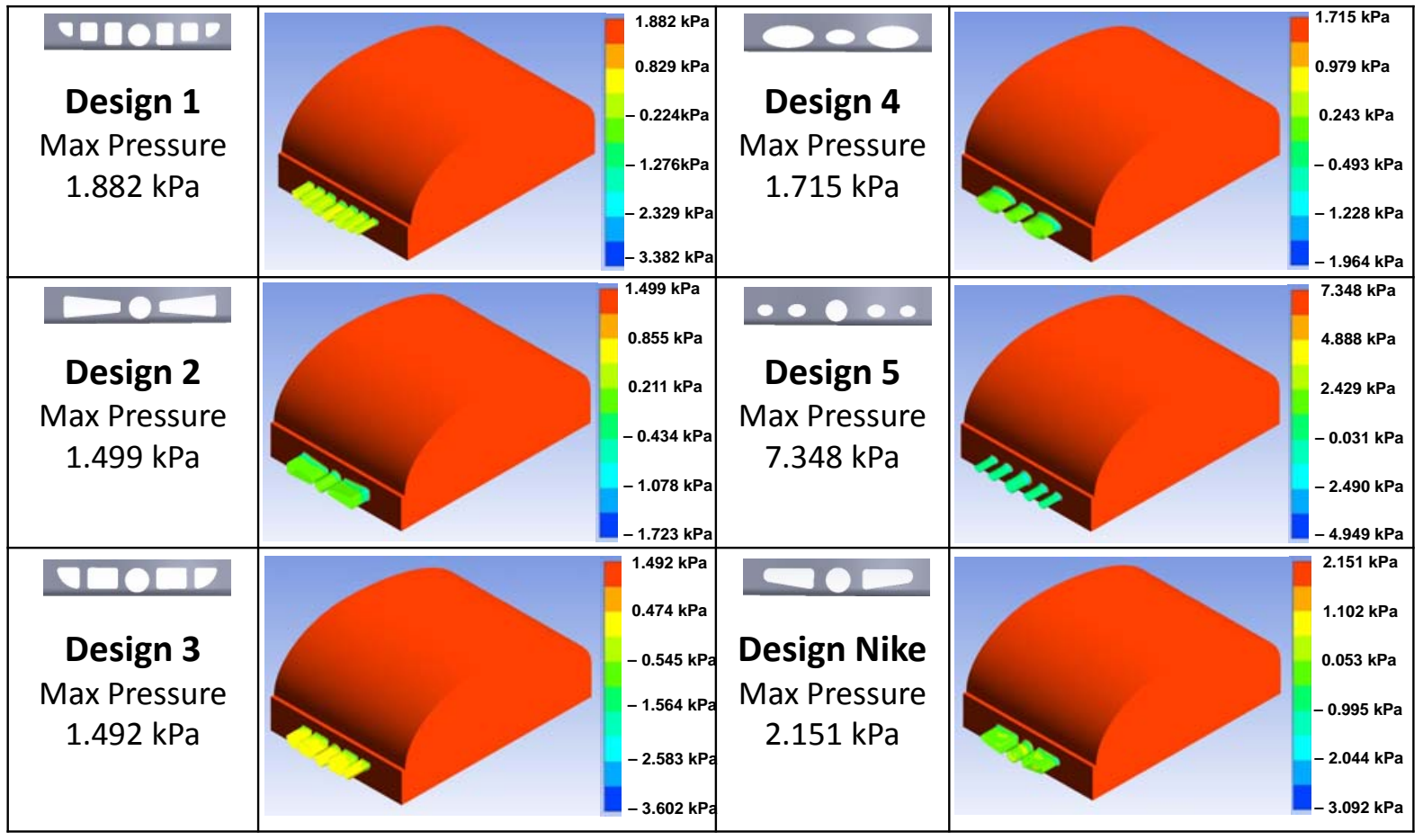

\section{B. The Effect of Exhale Velocity to Exhale Flow Rate}

Table III shows the results of air flow velocity obtained from the ANSYS simulation process. The highest velocity value was depicted by design number 5 (D5), which represents the smallest hollow area of the air flow channel $\left(19.66 \mathrm{~mm}^{2}\right)$. The lowest exhale velocity was presented by D2 with hollow area of $40.47 \mathrm{~mm}^{2}$. Meanwhile, the largest hollow area exhibited by D3 resulted in approximately $7 \%$ increment of average exhale velocity compared to D2.

The velocity value, depicted by the volumetric flow rate equation, depends on the flow rate value and inversely dependent on the area of the airflow channel that the air is moving through. The increase in air channel area decreases the airflow velocity in the mouth cavity model, thus increases the volume flow rate through the mouthguard's air flow channel. 
In correlation to the pressure build-up in the mouth cavity model, high flowrate is another main criteria in validating the design of the mouthguard's air flow channel. High exhale flowrate was found to improve the respiratory gas exchange rate in a study conducted on the effects of custom-fitted mouthguards during stress test of sixteen physically fit college students [8]. Therefore, improved endurance performance of the athletes is evidenced by the increase in exhale flowrate when wearing a mouthguard with an air flow channel.

TABLE III. Results of Air Flow Velocity

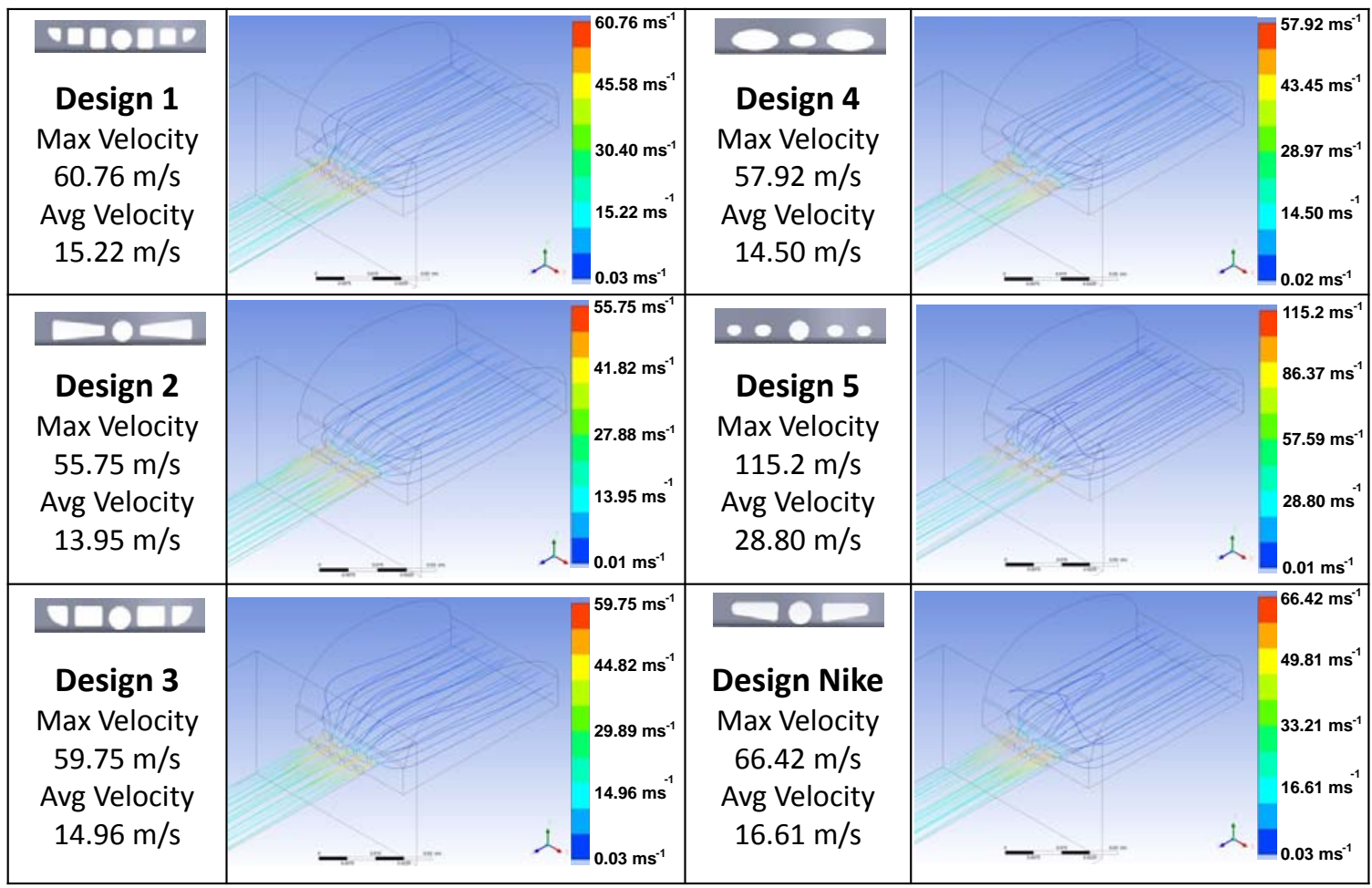

Fig. 4 depicts the results of exhale flow rate and exhale pressure through the various air channel design of the simulated mouthguards. The acceptable design that satisfies the lower exhale pressure is D1 to D4, while D3 exhibits the highest exhale air flow rate among others. It can be concluded from this study that D3 may be suggested for fabrication of the newly custom design of mouthguard. This was due to the following reasons; (i) lower build-up pressure which will reduce the effect of TMJ join disorder while improving athlete's performance and (ii) high exhale flow rate that allows higher endurance performance during sport activity.

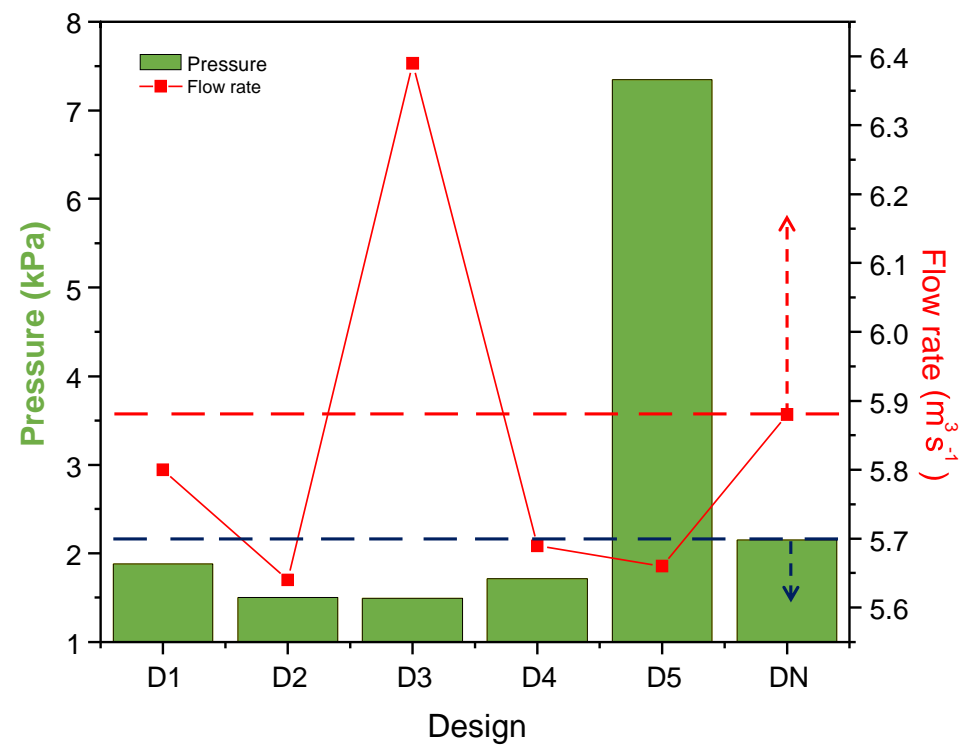

Fig. 4. Correlation between air pressure in mouth and the air flow through the mouthguard's air channel design. Dashed lines indicate benchmarked values and dashed arrows indicate to be achieved targets. 


\section{IV.CONCLUSION}

In this paper, it was attempted to develop a CFD simulation model that accurately correlates the breathing process through an air flow channel while wearing a mouthguard during sport activities. Simulation model was developed based on actual design of mouth mould wearing a mouthguard. The fitness of the model was verified employing a benchmark design from a readily available stock mouthguard. In this research, five newly designed mouthguard air channels were proposed against the benchmark model. Four out of the five models suggested lowest air flow pressure in both mouth cavity model as well as through the air channels compared to the base stock model. In addition, a reduction of below than $2 \mathrm{kPa}$ of exhale pressure through the air channels was observed on all the four proposed models. The best design from design number 3 (D3) of the mouthguard that justifies the low exhale pressure and high exhale flow rate may be proposed for fabrication.

\section{ACKNOWLEDGMENT}

The authors would like to thank the Ministry of Education Malaysia for the financial support via Exploratory Research Grant Scheme (ERGS - E042) and Universiti Tun Hussein Onn Malaysia for providing laboratory facilities.

\section{REFERENCES}

[1] Y. Maeda, D. Kumamoto, K. Yagi and K. Ikebe. "Effectiveness and fabrication of mouthguards". Dental Traumatology, Vol. 25, pp. $556-554$, Dec. 2009.

[2] T. Badel, V. Jerolimov and J. Pandurić. "Dental/orofacial trauma in contact sports and intraoral mouthguard programmes". Kinesiology, Vol. 39, pp. 97 - 105, May 2007.

[3] M. A. Mustapha, M. S. Wahab, and E. A. Rahim. "Analysis of air flow in the mouthguard design by using CFD approach". ARPN Journal of Engineering and Applied Sciences, Vol. 11, No. 2, pp. 7470-7474, June 2016.

[4] American Dental Association Division of Science. "For the dental patient. Keep sports safe--wear a mouthguard". J. Am. Dent. Assoc., vol. 143, pp. 312, Mar. 2012

[5] N. P. Chandler, N. H. Wilson, and B. S. Daber. "A modified maxillary mouthguard". British Journal of Sports Medicine, Vol. 21, pp. 27-28, June 1987.

[6] Improving physical performance The Role of Jaw-Repositioning. PhD Dissertation. The State University of New Jersey; 2012.

[7] D. Koc, A, Dogan and B. Bek. "Bite Force and Influential Factors on Bite Force Measurements: A Literature Review". Eur. J. Dent., vol. 4, pp. 223-232, Apr. 2010.

[8] D. P. Garner, W. D. Dudgeon, P. Timothy, E. J. Mcdivitt and T. P. Scheett. "The effects of mouthpiece use on gas exchange parameters during steady-state exercise in college-aged men and women”. J. Am. Dent. Assoc., vol. 142, pp. 1041 - 1047, Sept. 2011.

\section{AUTHOR PROFILE}

Erween Abd Rahim (E.A. Rahim) is an Associate Professor at the Universiti Teknologi Tun Hussein Onn Malaysia and the Head of the Precision Machining Research Centre at the Department of Manufacturing and Industrial Engineering, Faculty of Mechanical and Manufacturing Engineering, UTHM. 